\title{
Analysis of dimensional accuracy for micro-milled areal material measures with kinematic simulation
}

\author{
Katja Klauer $^{1}$ • Matthias Eifler ${ }^{2} \cdot$ Benjamin Kirsch ${ }^{1} \cdot$ Volker Böß $^{3} \cdot$ Jörg Seewig ${ }^{2} \cdot$ Jan C. Aurich ${ }^{1}$
}

Received: 20 January 2021 / Accepted: 3 July 2021 / Published online: 16 July 2021

(C) The Author(s) 2021

\begin{abstract}
The calibration of areal surface topography measuring instruments is of high relevance to estimate the measurement uncertainty and to guarantee the traceability of the measurement results. Calibration structures for optical measuring instruments must be sufficiently small to determine the limits of the instruments.

Besides other methods, micro-milling is a suitable process for manufacturing areal material measures. For the manufacturing by micro-milling with ball end mills, the tool radius (effective cutter radius) is the corresponding limiting factor: if the tool radius is too large to penetrate the concave profile details without removing the surrounding material, deviations from the target geometry will occur. These deviations can be detected and excluded before experimental manufacturing with the aid of a kinematic simulation.

In this study, a kinematic simulation model for the prediction of the dimensional accuracy of micro-milled areal material measures is developed and validated. Subsequently, a radius study is conducted to determine how the tool radius $r$ of the tool influences the dimensional accuracy of an areal crossed sinusoidal (ACS) geometry according to ISO 25178-70 [1] with a defined amplitude $d$ and period length $p$. The resulting theoretical surface texture parameters are evaluated and compared to the target values. It was shown that the surface texture parameters deviate from the nominal values depending on the effective cutter radius used. Based on the results of the study, it can be determined with which effective tool radius the measurands $S a$ and $S q$ of the material measures are best met. The ideal effective radius for the application considered is between 50 and $75 \mu \mathrm{m}$.
\end{abstract}

Keywords Kinematic simulation $\cdot$ Micro-milling $\cdot$ material measures

Nomenclature

A Tilt angle

ACS Areal crossed sinusoidal according to ISO 25178$70[1]$

AFL Areal plane surface material measure according to ISO 25178-70 [1]

Katja Klauer

katja.klauer@mv.uni-kl.de

1 Institute for Manufacturing Technology and Production Systems, Technische Universität Kaiserslautern, Gottlieb-Daimler Str, 67663 Kaiserslautern, Germany

2 Institute for Measurement and Sensor-Technology, Technische Universität Kaiserslautern, Gottlieb-Daimler Str, 67663 Kaiserslautern, Germany

3 Institute of Production Engineering and Machine Tools, Leibniz Universität Hannover, An der Universität 2, 30823 Garbsen, Germany

\begin{tabular}{|c|c|}
\hline$d$ & $\begin{array}{l}\text { Amplitude for chosen geometries (ACS, PPS ac- } \\
\text { cording to ISO } 25178-70[1] \text { ) }\end{array}$ \\
\hline$D$ & Tool path discretization \\
\hline$f_{t}$ & Feed per tooth \\
\hline$K_{n 1}$ & $\begin{array}{l}\text { Maximum normal curvature of the target geome- } \\
\text { try respectively profile }\end{array}$ \\
\hline$L$ & Distance between two tool parts \\
\hline$\lambda c, \lambda s$ & Filter nesting indices \\
\hline$n$ & Rotational speed \\
\hline$p$ & $\begin{array}{l}\text { Period length for chosen geometries (ACS, PPS } \\
\text { according to ISO } 25178-70[1] \text { ) }\end{array}$ \\
\hline$P P S$ & $\begin{array}{l}\text { Profile periodic sinusoidal according to ISO } \\
25178-70[1]\end{array}$ \\
\hline$S a$ & Arithmetic mean height \\
\hline Sa05-25 & $\begin{array}{l}\text { Arithmetic mean height after filtering with } \lambda \mathrm{c}= \\
25 \mu \mathrm{m} \text { and } \lambda \mathrm{s}=5 \mu \mathrm{m}\end{array}$ \\
\hline Sa80 & $\begin{array}{l}\text { Arithmetic mean height after filtering with } \lambda \mathrm{c}= \\
80 \mu \mathrm{m}\end{array}$ \\
\hline$S q$ & Root mean square height \\
\hline
\end{tabular}


Sq05-25 Root mean square height after filtering with $\lambda \mathrm{c}=$ $25 \mu \mathrm{m}$ and $\lambda \mathrm{s}=5 \mu \mathrm{m}$

Sq80 Root mean square height after filtering with $\lambda \mathrm{c}=$ $80 \mu \mathrm{m}$

$r \quad$ Tool radius (effective cutter radius according to [2])

$r_{\exp } \quad$ Effective cutter radius of tool $T_{\exp }$

$r^{*} \quad$ Contact point radius

$v_{c} \quad$ Cutting speed

$v_{f} \quad$ Feed rate

Tool

$T_{\exp } \quad$ Tool used for experimental investigation

\section{Introduction and state of the art}

In order to estimate the uncertainty of measurement and to guarantee the traceability of the measurement results, optical surface topography measuring instruments are calibrated. The lateral resolution of optical surface topography measuring instruments is in the micrometer range, and the resolution of the vertical axis is in the nanometer range. Therefore, the structures used for calibration must be sufficiently small.

In ISO 25178-70 [1], areal material measures for the calibration of optical surface topography measuring instruments are standardized. However, no manufacturing process is suggested for realizing the structures [1].

According to Cheng and Dehong, micro-milling is a suitable process for the manufacturing of structures in the micrometer range [3]. Brinksmeier stated that especially micromilling with ball end mills allows the manufacturing of small structures with convex or concave structural details or freeform surfaces [4]. Initial feasibility studies of Nemoto et al. have shown that micro-milling with ball end mills is also suitable for manufacturing of areal material measures [5]. Leach at al. also manufactured material measures by micromilling [6]: the focus of their research was on reducing costs through replication.

In experimental studies of ball-end milling by the authors, the process parameters were systematically investigated and selected in such a way that areal material measures can be manufactured with very high repeatability $[7,8]$.

For the manufactured topographies, it is however a challenging task to estimate which deviations from the target geometry are caused by kinematic effects and which deviations are related to other influences (e.g., material properties, chosen cutting parameters, or statistical or systematic errors during manufacturing). Simulation tools allow the kinematic effects to be considered precisely and isolated from other effects. In micro-machining, different effects (material separation, kinematic effects, effects due to environmental influences such as vibrations or temperature fluctuations, etc.) overlap the kinematic effects and cause roughness variations in a very similar order of magnitude. For experimental topographies, there are deviations associated with the measuring instrument and its interaction with the workpiece in the measured topographies. Also, relevant microstructural features that cannot be resolved with conventional surface topography measuring instruments may occur. Thus, an experimental determination of the corresponding microstructures is challenging or even impossible.

According to Arrazola et al., the dimensional accuracy of a manufactured structure is one of the possible outputs of a machining simulation [9]. These are particularly useful when analytical models cannot be applied. This is the case when irregular material measures are to be manufactured by micro-milling, which are based on real component surfaces. There are novel investigations by the authors on the manufacturing of areal material measures based on real component surfaces that represent irregular surface structures and allow a holistic performance verification of the measuring instrument [10]. For these structures, analytical estimations regarding the suitability of the micro-milling tool size for the manufacturing of the structures are not useful.

By now, the manufacturing feasibility of the examined structures is determined with the aid of areal morphological filtering. Also for ultraprecision (UP) turning of profile calibration artifacts, Eifler confirmed that the size of the tool (corner radius and tool included angle) determines the minimum structural size of the manufactured profile details [11] (see Figure 1).

Morphological filtering was also already used by Weckenmann et al. [12] and Krüger-Sehm et al. [13] for the design of calibration standards, however, features the disadvantage that the direction of the manufacturing process is not taken into account. The tool path is not considered during the filtering operation. The influence of the kinematics of the machining process is neglected.

Even without a complete implementation of a morphological filter but based on a comparison between the curvature of the surface to be manufactured and the curvature of the tool, it is possible to predict whether the target geometry can be produced with the respective tool (see Figure 1). Choi and Jerard described this relationship analytically [14] with the following formula:

$K_{n 1}>\frac{1}{r}$

where $K_{n 1}$ is the maximum normal curvature of the target geometry, and $r$ is the effective tool radius of the ball end milling tool. However, this model reaches its limits when surfaces are considered which cannot be easily described analytically. In addition, the feed path is not considered in this formula either. 
Figure 1 Simulation of the machining process based on a morphological closure and comparison of the curvatures of the tool and target profile

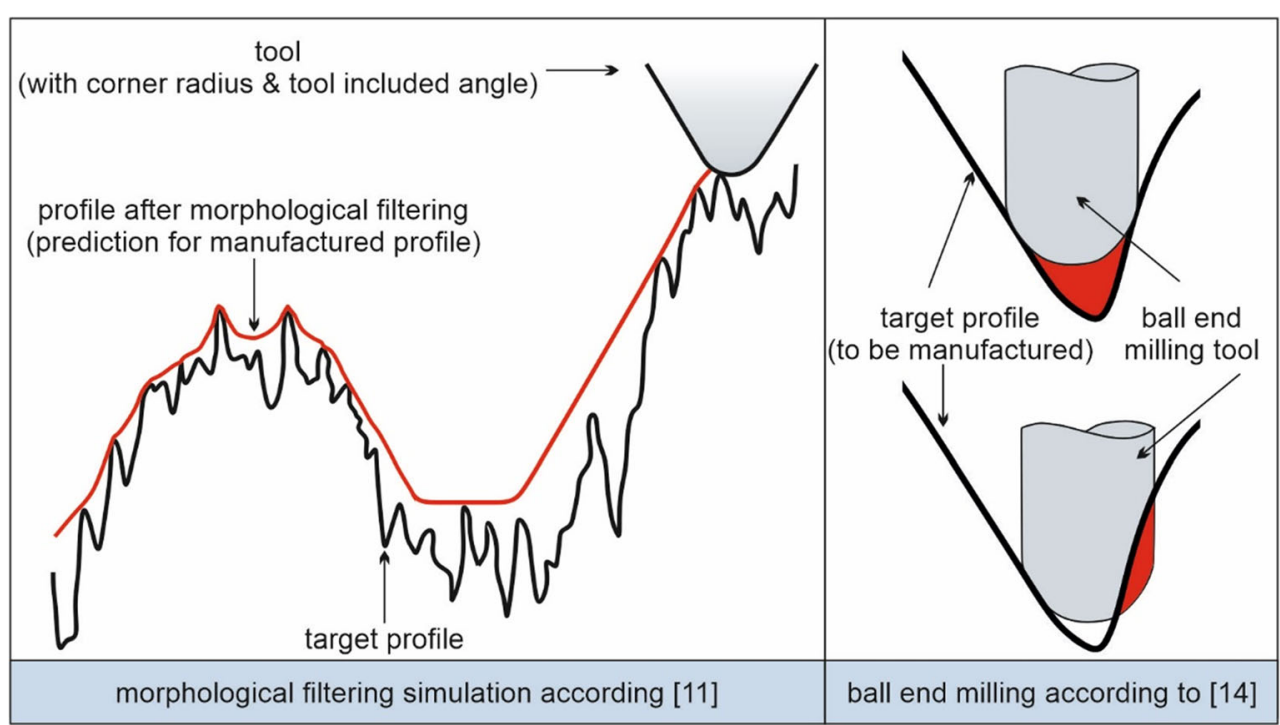

In the field of manufacturing technology, kinematic simulations are used to simulate the relative motion of the tool and workpiece. The engagement of the tool and workpiece is determined in discrete time steps, and the resulting shape of the manufactured workpiece is calculated. This method includes the motion information of the tool path. Some of the authors carried out kinematic simulations especially for ball-end milling [15]: the areal surface topography was predicted for ballend milling based on the results. In many other investigations, in which different simulation environments were used, the resulting kinematic roughness by the milling tool was also investigated. For example, Tapoglou and Antoniadis modeled the resulting roughness of the workpiece surface using the exact geometry of the cutting tool [16]. Their simulation was embedded in a commercial CAD environment. Also, Wojciechowski et al. [17], Zhang et al. [18], and Pimenov et al. [19] investigated the surface quality during milling in the macroscopic range (tool radius $r>>1 \mathrm{~mm}$ ): The influence of the tool displacement [17], the influence of the corner radius and tool diameter [18], or the effect of the relative position between workpiece and tool [19] was investigated. Based on experimental validation tests, it was shown that kinematic simulations can be used to predict process results.

The numerous procedures for investigating the kinematic influence that exist for conventional milling cannot be applied directly to micro-milling. The simulation must be adapted to the special aspects of micro-machining. Kinematic simulations in the field of micro milling already exist in the literature, but there is still a great need for research in this area [20]. The influences on the kinematic roughness by the inclination angle [20] and the cutting parameters [21] have already been investigated in simulations. All these studies on milling (both

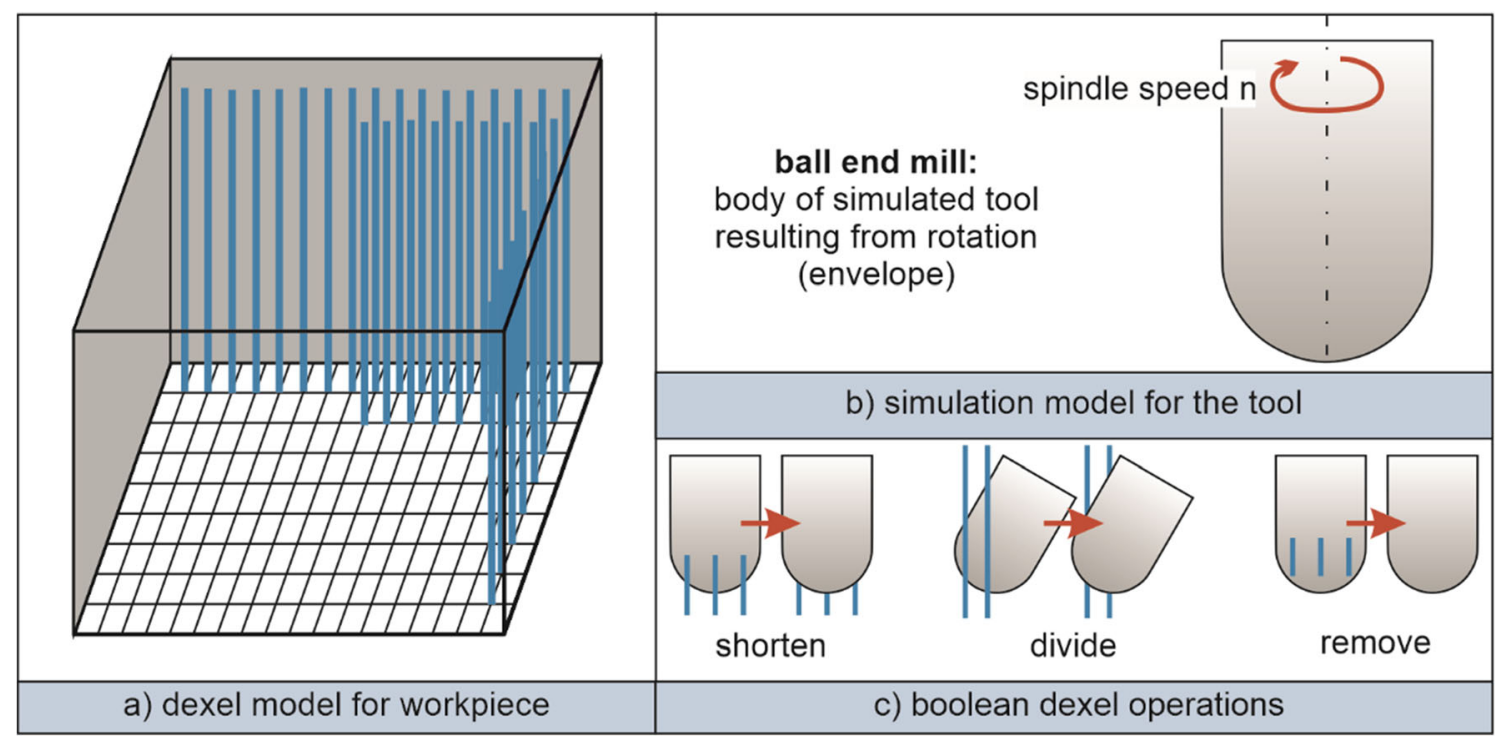

Figure 2 Dexel model (a), simulation model for the tool (b), and boolean dexel operations (c) according to Denkena et al. [31] 
conventional milling and micro-milling) have in common that they do not investigate the influence of the effective cutter radius on the dimensional accuracy of the manufactured structures. There is a particular need for research at this point. Especially for the design of calibration standards, this open research gap must be considered.

In the field of ultra-precision machining, dimensional accuracy studies do exist. However, these focus on kinematics of the machine tool used [22] or tool de-centering [23] and the selection of the feed path [24]. Form deviations caused by the tool geometry are not considered. Accordingly, these studies cannot be transferred to the application case of micro-milling.

In general, however, based on this state of the art, the performance of a kinematic simulation seems to be suitable for the investigation in this application case.

In a kinematic simulation, the workpiece is spatially discretized. According to Antoniadis et al., the choice of discretization strongly influences the efficiency of the simulation [25].

The workpiece model used in the study by Denkena et al. is the dexel model [31] (see Figure 2a). There are several different names for the discrete surface representations, which were listed by Choi and Jerard: e.g., "dexel, z-buffers, z-maps or surface point sets" [14]. The word dexel consists of the two compound words "depth" and "pixel" according to Niebuhr [26]. Another definition of the word dexel is "depth element" according to van Hook [27] or "discrete points" which are aligned over a regular grid according to Börner et al. [28]. Besides the dexel model, Denkena and Tönshoff listed several other discretization models for the workpiece's geometry, such as the voxel model or the polyhedron model [29]. Lee named the decisive advantage of the dexel model with regard to other models [30]: the cutting operations do not have to be calculated in three dimensions, but only as a one-dimensional intersection of the tool with the respective dexel (see Figure 2c).

In addition to the workpiece, the tool must also be modeled for the simulation. In most applications with rotating tools, it is sufficient to consider the body of the tool resulting from the rotation (envelope curve) according to Denkena and Tönshoff [29] (see Figure 2b). According to Börner et al., this simplified model is often used for the determination of cutting forces, temperature, or collision calculation [28].

Our study examines the kinematically induced deviations caused by the effective tool radius (resulting radius for rotating tool; definition according to [2]) during the manufacturing of areal material measures with the aid of kinematic simulations that use the Dexel method and consider the path of the tool. The aim of this study is not only to find out at which effective cutter radius the structure can no longer be manufactured correctly but also to determine which deviations occur quantitatively in the respective structure and how the corresponding surface texture parameters change. With this information, the tool radius of the milling tool is already taken into account in the design process by determining possible deviations that are caused otherwise. In the future, only those calibration structures are to be manufactured which do not show any deviations from the target geometry due to the size of the tool radius used. For benchmarking, the experimental results are described in Section 2, before Section 3 describes the simulation model.

\section{Experimental investigation}

The experimental investigations were previously described in [32]. To present an overview of the experimental tests and the resulting requirements for the kinematic simulation, this section summarizes the experimental setup and results.

\subsection{Experimental setup}

The tests were carried out on the LT Ultra machine tool MMC $600 \mathrm{H}^{1}{ }^{1}$ The tested tool $T_{\exp }$ is made of monocrystalline diamond and is a single-edged tool (see Figure 3). It has an effective cutter radius of $r_{\text {exp }}=100 \mu \mathrm{m}$ and a cutting edge radius $<<1 \mu \mathrm{m}$ which is not measurable with optical measuring instruments and therefore estimated based on scanning electron microscope images. A tool with a simple geometry (see Figure 3) was selected for the experiments, so that it can be easily simulated by its envelope curve for the kinematic simulation.

The following cutting parameters were used to machine brass $\mathrm{CuZn} 39 \mathrm{~Pb} 3$ in the experimental investigations (see Table 1).

With these constant cutting parameters, four different material measures according to ISO 25178-70 [1] were manufactured (see Figure 4a). The geometries with sinusoidal structures (ACS, PPS, and PPS rotated) have a period length of $p=200 \mu \mathrm{m}$ and amplitude of $d=10 \mu \mathrm{m}$. The different geometries were chosen to be able to investigate different engagement conditions of the tool. The local cutting depth and local gradient of the surface vary for the chosen geometries.

A tilt angle $A$ was set to avoid a cutting speed of zero. The contact point between the tool and the workpiece depends on the tilt angle $A$ and is in a distance $r^{*}$ to the tool axis (see Figure $4 \mathrm{~b}$ ). The influence of the tilt angle on the dimensional accuracy and roughness of the manufactured geometries was investigated in the experimental study [32] for nine different tilt angles $\left(A 1=20^{\circ}, A 2=25^{\circ}, A 3=30^{\circ}, \ldots, A 9=60^{\circ}\right)$.

\footnotetext{
${ }^{1}$ Naming of specific manufactures is done solely for the sake of completeness and does not necessarily imply an endorsement of the named companies nor that the products are necessarily the best for the purpose.
} 
Figure 3 Chosen tool for experimental investigation

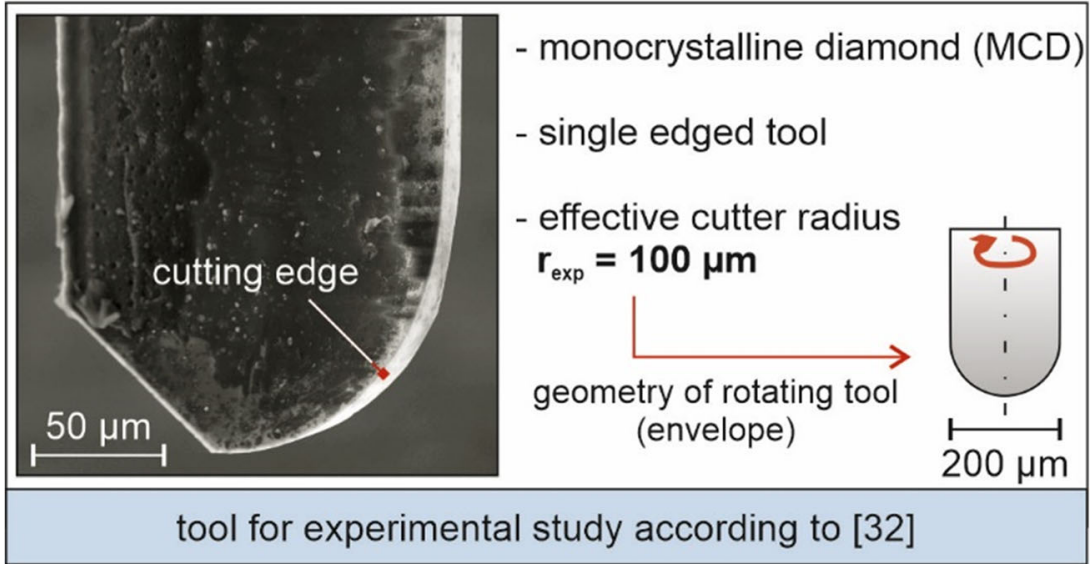

The geometries were all manufactured with a meandershaped tool path (alternating tool movement in up and down milling) (see Figure 4c)).

\subsection{Measurement and evaluation for experimental investigation}

For the evaluation of four measurements of each manufactured material, measures were performed with a confocal microscope featuring a $20 \times$ magnification and a numerical aperture (NA) of 0.6. After the extraction of a central evaluation area for each measurement, standardized areal surface texture parameters $S a, S q$ were determined as described in ISO 25178-2 [33]. Additionally, a bandwidth limitation according to [32] was applied to evaluate the extent of short wavelengths roughness. In doing so, the two filtering settings with the nesting indices

i) $1 \mathrm{~s}=5 \mu \mathrm{m}$ and $\mathrm{lc}=25 \mu \mathrm{m}$ and

ii) $1 \mathrm{c}=80 \mu \mathrm{m}$

were applied. Subsequently, the corresponding areal surface texture parameters of the bandwidth-limited surface topographies $S a 05-25, S q 05-25, S a 80$, and $S q 80$ were determined.

\subsection{Results of experimental investigation}

The experimental results that will be compared to the simulation results in this paper are given in Table 2 . In the table, the

Table 1 Cutting parameters for tool $T_{\exp }$ according to [32]

\begin{tabular}{ll}
\hline Parameter & Value \\
\hline Spindle speed $n$ & $60,000 \mathrm{rpm}$ \\
Feed per tooth $f_{t}$ & $0.16 \mu \mathrm{m}$ \\
Feed rate $v_{f}$ & $10 \mathrm{~mm} / \mathrm{min}$ \\
\hline
\end{tabular}

maximum value (max) and the minimum value (min) as well as the mean value (mean) over all tested tilt angles for the measured areal surface texture parameters are given for the respective geometries. In the experimental investigations, it can be shown that the resulting surface topographies are influenced by the selection of the tilt angle (see Figure 5).

\section{Simulation}

A new simulation model was built, time optimized, validated, and applied.

\subsection{Model design}

The simulation was performed using IFW CutS, a kinematic simulation software developed at the Institute of Production Engineering and Machine Tools Hannover. Within this study, only the kinematic deviations resulting from the tool radius (effective cutter radius) were investigated by applying an envelope curve model for the tool. Using the simplified geometry of the tool reduces the necessary discretization density of the model. The envelope curve model also has the advantage that it is not necessary to define a rotation axis as well as a rotation movement for the tool, as the shape which results by the rotation is already simulated. This again reduces the simulation time.

When investigating the influence of the tool radius (effective cutter radius) on the manufactured geometry, the following general behavior is expected depending on the radius size:

(1) For very small tool radii $(2 \cdot r<<$, with $p=$ period length of the sinusoidal structures):

i) The target geometry of the material measure is imaged very well (high dimensional accuracy)

ii) The short-wavelength roughness* (due to the individual tool paths) in $x_{M}$-direction is higher than for larger tool 


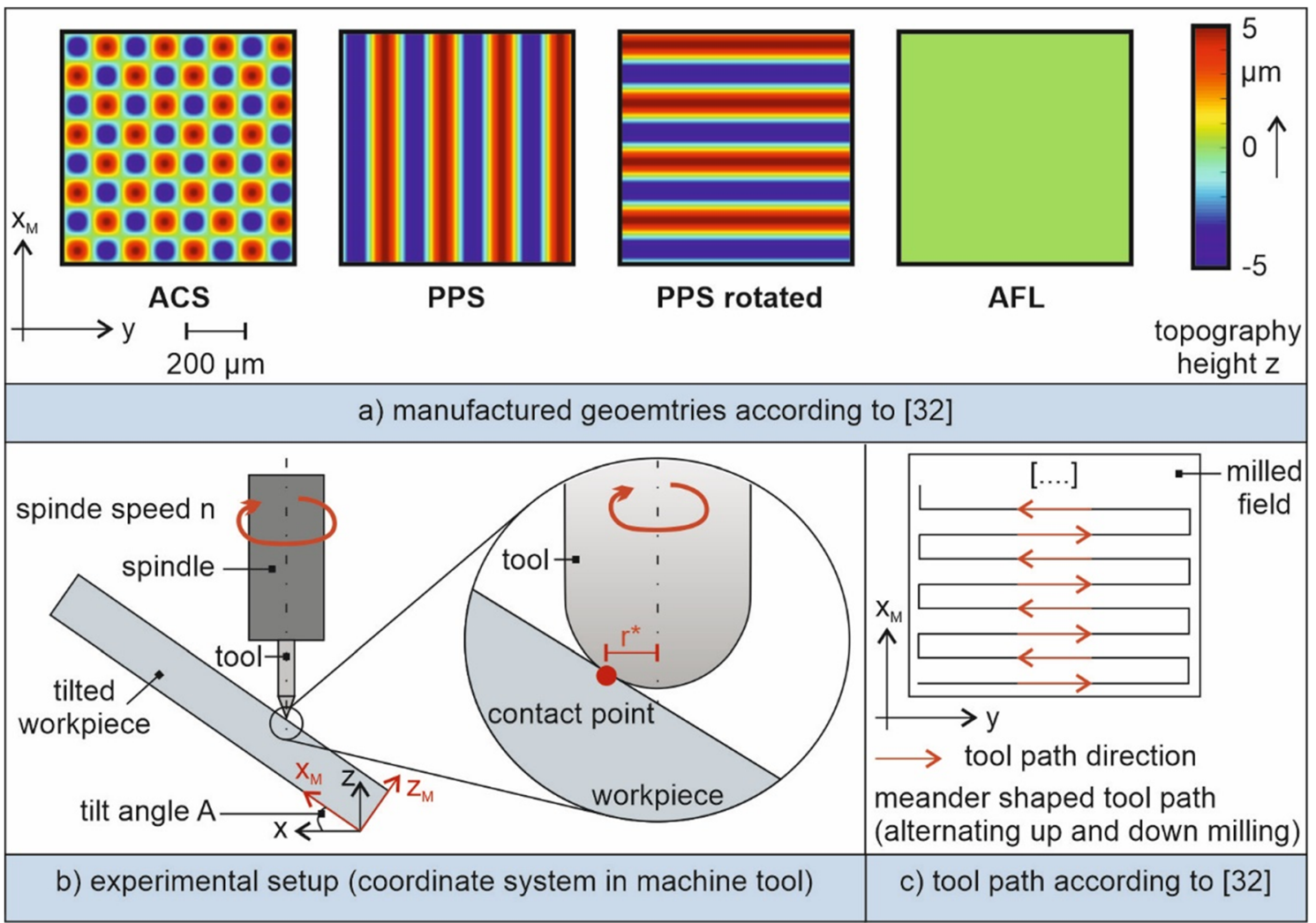

Figure 4 Chosen geometries and experimental setup with the chosen tool path

diameters for a constant distance between two tool paths $L$ (see Figure 6)

(2) For larger tool radii $(2 \cdot r \sim p)$ :

i) Deviations from the target geometry occur (reduced dimensional accuracy)

ii) The short-wavelength roughness* in $x_{M}$-direction is smaller for a constant distance between two tool paths $L$ than with very small tool diameters (see Figure 6)

*The described short-wavelength roughness results from the adjacent individual tool paths in $x_{M}$-direction. Analytical

Table 2 Results of the experimental investigation (for tool $T_{\exp }$ with $\left.r_{\text {exp }}=100 \mu \mathrm{m}\right)-$ summary of the areal surface texture parameters

\begin{tabular}{llllllll} 
Geom. & \multicolumn{2}{l}{$\mathrm{Sa}(\mu \mathrm{m})$} & & \multicolumn{2}{l}{$\mathrm{Sq}(\mu \mathrm{m})$} \\
\cline { 2 - 3 } & $\max$ & $\min$ & mean & & $\max$ & $\min$ & mean \\
\hline ACS & 2.044 & 2.019 & 2.034 & 2.480 & 2.448 & 2.469 \\
PPS & 3.160 & 3.114 & 3.132 & 3.522 & 3.472 & 3.492 \\
PPS rotated & 3.078 & 2.962 & 3.038 & 3.437 & 3.365 & 3.404 \\
AFL & 0.134 & 0.017 & 0.038 & 0.172 & 0.021 & 0.048 \\
\hline
\end{tabular}

calculation formulas for the roughness resulting from the distance between two tool paths and the effective cutter radius exist, for example, according to Hock [34].

The simulated short-wavelength roughness in feed direction $y$ of the individual paths does not correspond to the predictions for the experimental model due to the choice of the tool model: The real geometry of the tool was not simulated, but its envelope was used for the simulation. The predicted kinematic roughness in $y$-direction results from the rotational and translational motion of the cutting edge. In the simulation, however, only the envelope curve is simulated, which only moves translatory. However, the influence of the kinematic roughness caused by the real movement of the cutting edge on the resulting dimensional accuracy is negligibly small if small feeds per tooth for tool radii which are very large in relation thereto are used. In the experiments a feed per tooth $f_{t}=0.25 \mu \mathrm{m}$ is set (see, e.g., [32]) and a tool with an effective cutter radius of $r 1=100 \mu \mathrm{m}$ is used. According to Hock, the theoretical roughness $R z$ can be estimated [34]:

$R z \approx r-\sqrt{\frac{4 \cdot r^{2}-f_{t}^{2}}{4}}$.

This equation is an approximation and is only valid for planar surfaces. If curved surfaces are considered, further effects, which were described for example by Choi and Jerard, must be considered [21]. For this study, however, formula (2) 


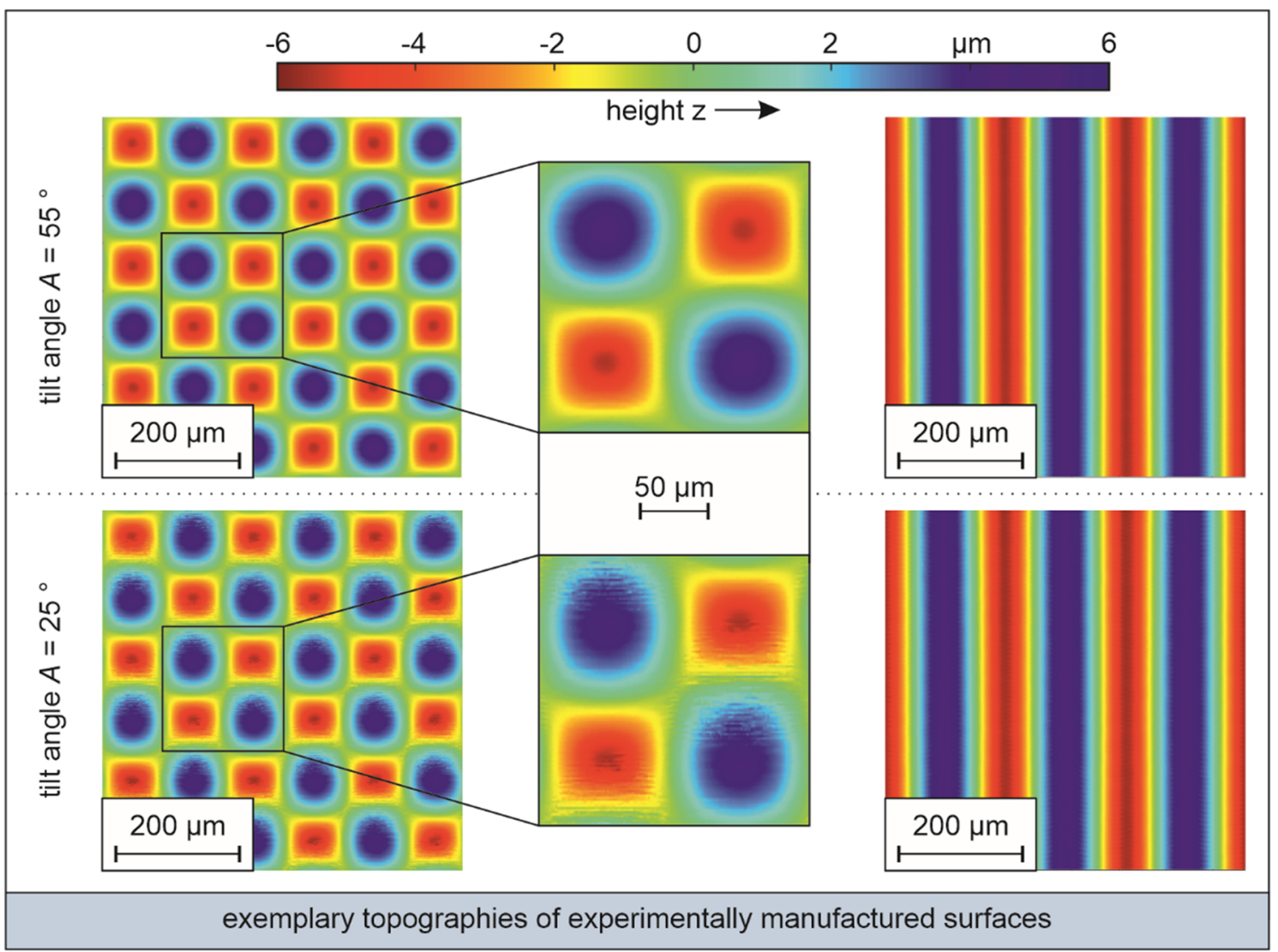

Figure 5 Topographies of experimentally manufactured surfaces

is only used to determine an order of magnitude for the kinematic roughness in the feed direction.

For a tool with a radius of $r=100 \mu \mathrm{m}$ and a feed per tooth of $f_{t}=0.25 \mu \mathrm{m}$, the theoretical roughness in the middle of the milled slot is $R z=0.078 \mathrm{~nm}$. Therefore, the mentioned adjustments are acceptable in the simulation.
In micro-milling, the size of the tool diameter is limited due to the material properties of the cutting tool material and due to the technical limits in tool manufacture. However, the structures of the target geometries for the areal material measures should be as small as possible. Therefore, the case for larger tool diameters $(2 \cdot r \sim p)$ is of interest when designing the

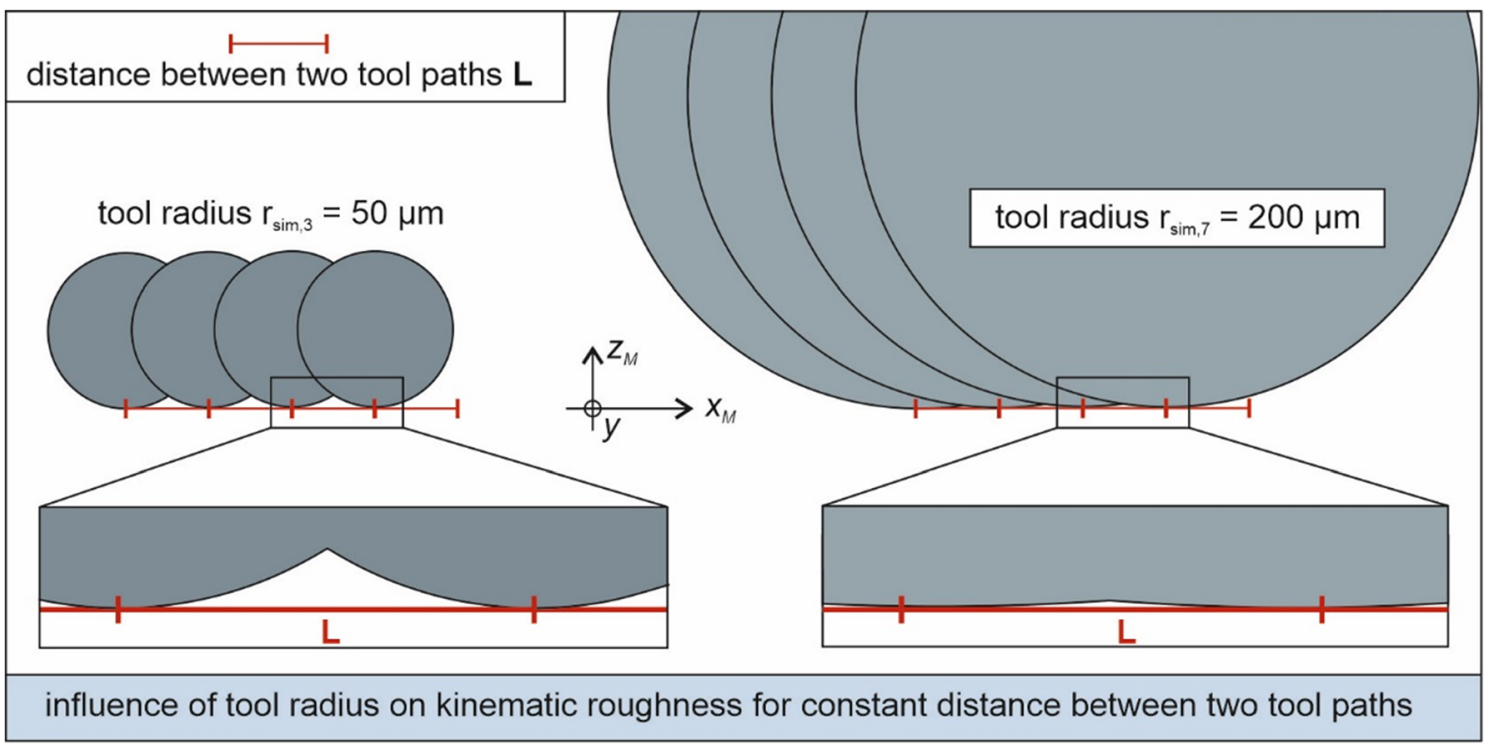

Figure 6 Influence of the tool radius on kinematic roughness in $x_{M}$-direction 
dataset for the manufacturing of areal material measures by micro-milling.

The tool's geometry based on the envelope curve was constructed in Siemens $\mathrm{NX}^{1}$ and afterwards imported into CutS as an STL file (angular tolerance: $1^{\circ}$, edge tolerance $0.0025 \mathrm{~mm}$, see Figure 7).

The relative movement between the tool and the workpiece was implemented via the G-Code which was also used for the experimental manufacturing of the material measures. The distance between two tool paths (meander-shaped tool path, see Figure $4 \mathrm{c}$ ) is $L=4 \mu \mathrm{m}$ and the discretization in $y$-direction along a tool path is $D=0.8 \mu \mathrm{m}$.

The workpiece was discretized with a dexel model. The following discretization for the dexel model was calculated in the first step:

- in $x_{M}$-direction:

$$
\begin{aligned}
\Delta x_{M} & =x_{M, \text { min }} \\
N_{x_{M}} & =\frac{B_{x_{M}}}{\Delta x_{M}}
\end{aligned}
$$

- in $y$-direction:

$$
\begin{aligned}
& \Delta y=y_{\min } \\
& N_{y}=\frac{B_{y}}{\Delta y}
\end{aligned}
$$

$\Delta x_{M}$ or $\Delta y$ is the spacing between two dexels in $x_{M^{-}}$or $y$ direction. $N$ is the number of dexles, and $B$ is the width of the entire geometry in the respective direction. $x_{M, \min }$ or $y_{\min }$ is the minimum distance between two points in the respective direction in the G-Code used for the generation of the material measures.
Only the dexels that are touched by the tool at the end of a simulation time step are cut by the tool in the simulation. The feed rate must be adjusted in the simulation so that the tool only moves one dexel per simulation time step. The feed rate $v_{f \text { sim }}$ was adapted to the minimum discretization in $x$-direction of the G-Code:

$v_{f, \operatorname{sim}, x}=\frac{B_{x_{M}}}{N_{x_{M}} \cdot t_{s}}$

with $t_{s}$ as time of a simulation step. This calculation of the simulative feed rate guarantees that each point of the G-Code (to which a dexel is assigned based on the previous calculation) is reached by the tool, and the boolean dexel operation is performed. The calculation of the simulative feed rate thus ensures that the same points are reached as in the experimental investigation. Since the simulated motion for the envelope curve of the tool is a purely translational motion and effects of superposition of the rotational and translational motion of the cutting edge is not considered in this simulation. It is irrelevant for the simulation results that the feed rate in the simulation deviates from the feed rate from the experimental investigation. It is only important that the same points are imaged by the tool in both cases (simulative and experimental). The machine tool performs a linear interpolation between two successive points during the experimental investigations. In the simulation, the tool is set to the specific position at the end of each timestep. There is no interpolation because no sweep volume was calculated in this work. The sweep volume has not been calculated because the distance between the dexels is so small in relation to the size of the effective cutter radius of the tool that the resulting deviation is negligible. The mesh size and the resulting feed rate for the G-Code used, calculated based on the equations described, are shown in Figure 8 (first model). When calculating the number of dexels in $x_{M}$-direction, there is one special feature of the G-Code to consider: the point spacing in the G-Code is not equidistant in this direction. This stems from the fact that the distance in $y$ direction was kept equidistantly $(D=0.8 \mu \mathrm{m})$ and the

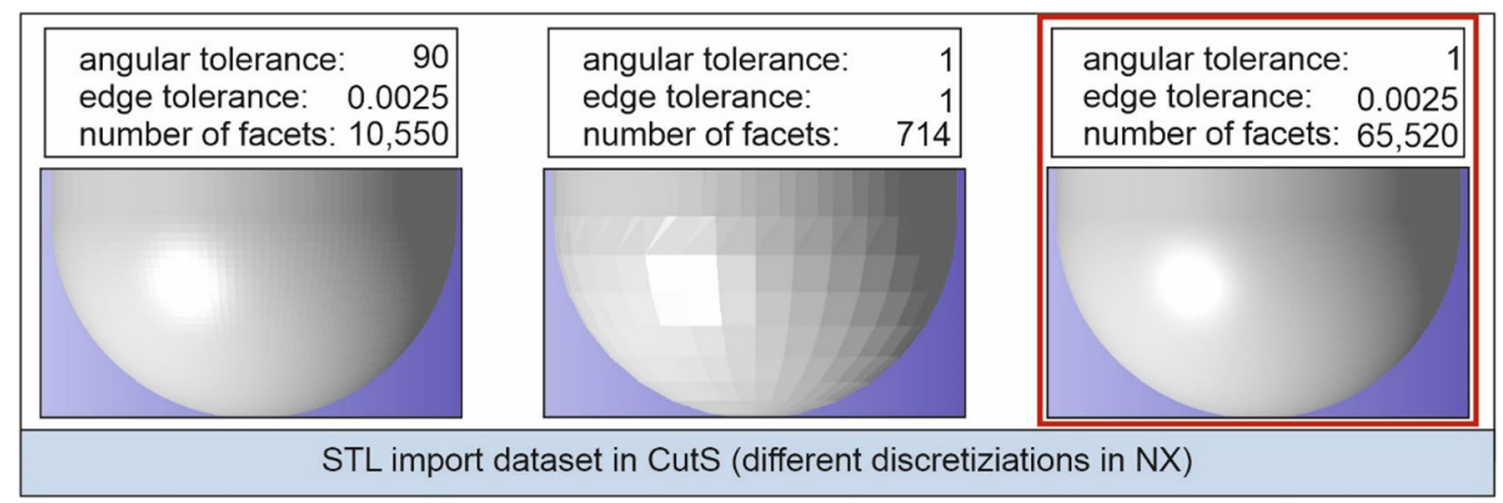

Figure 7 Tool discretization with different angular and edge tolerances 


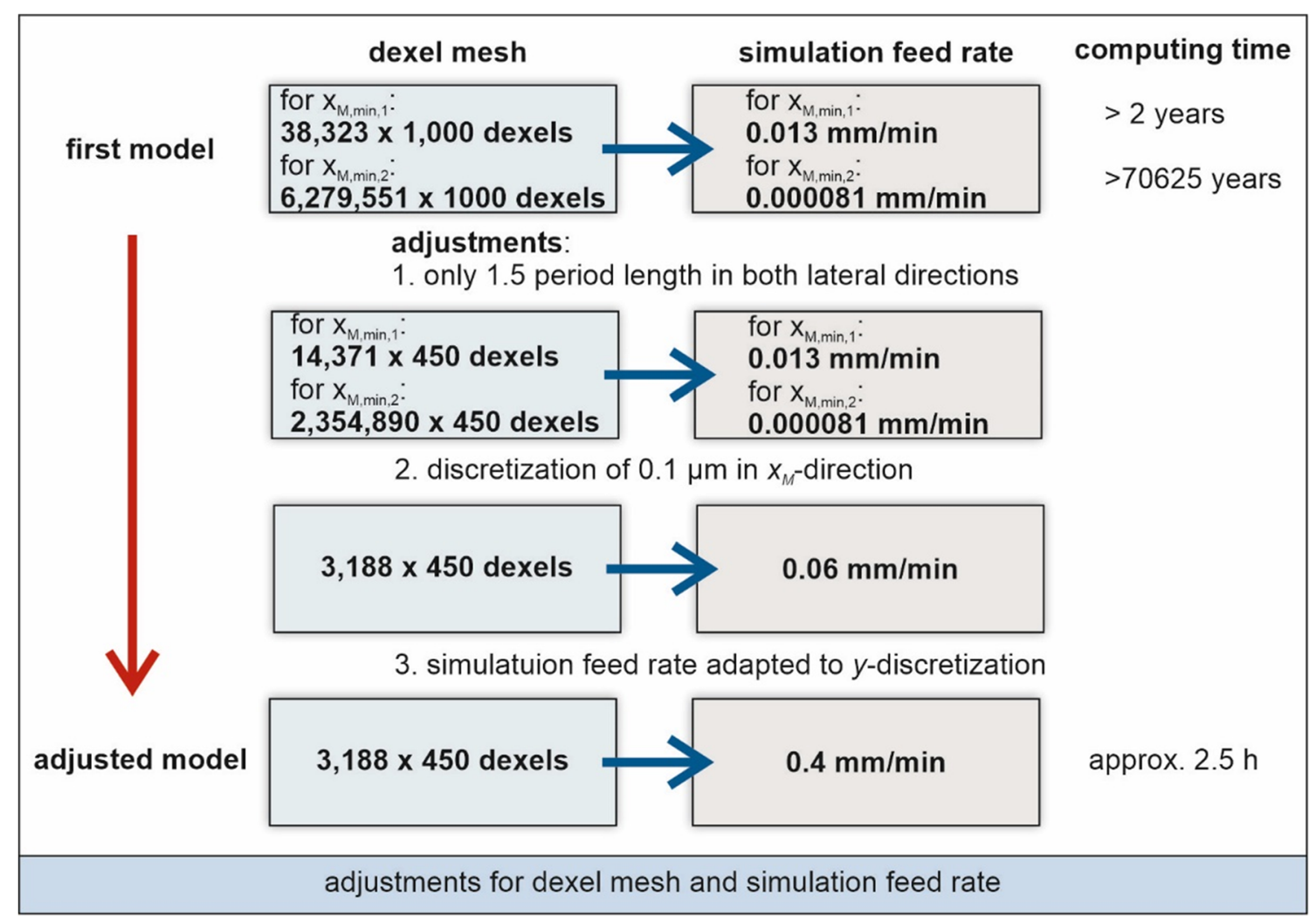

Figure 8 Mesh sizes and adjustments

resulting $z_{M^{-}}$and $x_{M^{-}}$-values were calculated at this point. Due to the sinusoidal structure, the distances in $z_{M^{-}}$and $x_{M^{-}}$ direction are not equidistant. Two different dexel discretizations were therefore calculated in $x_{M}$-direction for the workpiece model (see Figure 8):

(1) A discretization that is based on the average distance of all occurring distances in the $x_{M}$-direction $\left(x_{M, \min , 1}=\right.$ $0.02218 \mu \mathrm{m})$

(2) A discretization that results from the minimum distance from the G-code in $x_{M}$-direction $\left(x_{M, \min , 2}=0.00013536\right.$ $\mu \mathrm{m})$

The computing time was calculated based on a reference model for the simulation, under the assumption that the computing time for an increasing dexel number and reduction of the simulative feed rate increases linearly. As for both theoretically calculated meshes (see Figure 8, first model) and the adapted simulative feed rates a calculation time of several years would result for a common desktop PC, the discretization of the dexel mesh and the simulation feed rate $v_{f \text { sim }}$ were adjusted with the following modifications (see Figure 8):

(1) Only 1.5-period lengths of the periodic structures in both lateral directions were machined in the simulation. Although one-period length would be sufficient, the machined section was enlarged to 1.5 period lengths in the simulation as end effects occur which have to be cut out

(2) In $x_{M}$-direction, the minimum spacing of $0.1 \mu \mathrm{m}$ was taken into account, since the lateral spacing of topography measuring instruments is usually larger. When comparing the experimentally and simulatively determined
Table 3 Surface texture parameters for different meh sizes and feed rates

\begin{tabular}{llllll}
\hline Tool radius $(\mu \mathrm{m})$ & $\begin{array}{l}\text { Dexel mesh } \\
\left(x_{M} \times y\right)\end{array}$ & $\begin{array}{l}\text { Simulation feed } \\
\text { rate }(\mathrm{mm} / \mathrm{min})\end{array}$ & $S a(\mu \mathrm{m})$ & $S q(\mu \mathrm{m})$ & $\begin{array}{l}\text { Computing } \\
\text { time (h) }\end{array}$ \\
\hline 50 & $40000 \times 450$ & 0.4 & 2.022 & 2.484 & 24 \\
50 & $3188 \times 450$ & 0.06 & 2.022 & 2.484 & 36 \\
50 & $3188 \times 450$ & 0.4 & 2.022 & 2.484 & 2.5 \\
\hline
\end{tabular}


datasets, wavelength smaller $<0.1 \mu \mathrm{m}$ could not be taken into account because they could not be measured for the experimentally manufactures samples. Thus, $\Delta x_{M}$ was set to $0.1 \mu \mathrm{m}$ for the new adapted mesh

(3) The main cutting movement is in the $y$-direction, and the simulation feed rate $v_{f \text {,sim }}$ has been adapted to the discretization in $y$-direction to $v_{f, \text { sim }}=0.4 \mathrm{~mm} / \mathrm{min}$ :

$v_{f, \operatorname{sim}, y}=\frac{B_{y}}{N_{y} \cdot t_{s}}=0.4 \mathrm{~mm} / \mathrm{min}$

In a verification study, it was examined whether the adjustments made to reduce the computing time are permissible (see Table 3). The adjusted model cannot be compared with the first model because the first model requires a theoretical computing time of several years. Therefore, starting from the adjusted model, a model with a smaller discretization in $x_{M}$-direction and a model with a smaller simulative feed rate was selected. The next finer dexel mesh (smaller dexel discretisation) starting from the adjusted model was considered for two different cases $\left(x_{M \text {,min, },}: 14,371\right.$ dexels and for $x_{M \text {,min, } 2}: 2,354,890$ dexels). Therefore, the maximum possible number of dexels in $x_{M}$-direction that the used computer could calculate (for constant dexel number of 450 dexels in $y$-direction) was selected: 40,000 dexels in $x_{M}$-direction.

Additionally, the next lower simulative feed rate of 0.06 $\mathrm{mm} / \mathrm{min}$ was used as slower feed rate.

The evaluation of the parameters $S a$ and $S q$ was identical to the evaluation of the experimental results (see Section 3.2). The considered surface texture parameter values were identical for all mesh-feed combinations down to the nanometer range (see Table 3 ). The adjustments for the simulation model are therefore valid.

\subsection{Validation}

In the next step, the simulation model was validated by a comparison of the simulated data with the experimental data.

In the simulation, the deepest point of the ball end mill (point on the rotation axis) was used as contact point (see Figure 9). This point was defined because otherwise a new calculation of the contact point would always have to be carried out at the beginning of the simulation for different tilt angles and tool diameters. In order to eliminate this potential source of error at the beginning of the simulation, the contact point was defined in a standardized way.

In the experiment, the distance between tool and workpiece is gradually reduced until a chip is visible in the microscope camera for process monitoring. If the first chip is detected, this position in z-direction is defined as zero point.

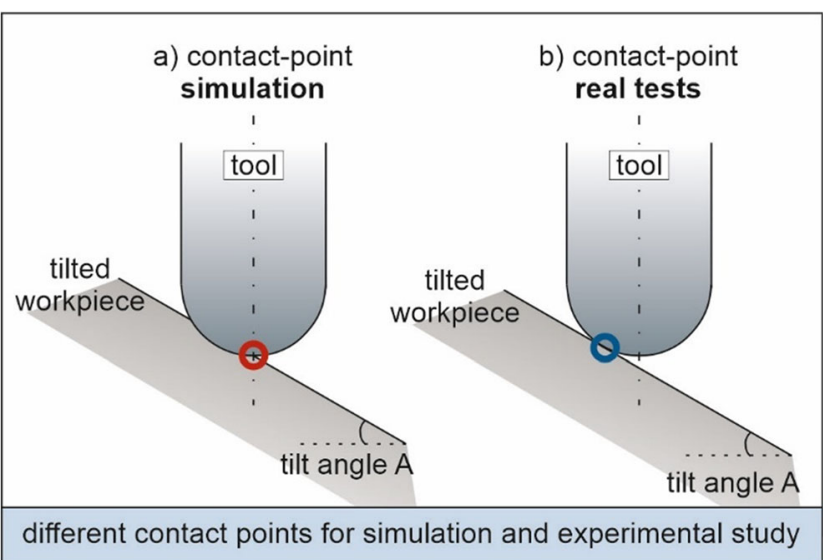

Figure 9 Contact point between tool and workpiece; simulation vs. experimental investigation

The dimensional accuracy of the experimentally manufactured and simulated geometry is identical as long as the tool is only in contact with its radius but not with its shaft (see Figures 10 and 11). Depending on the position of the contact point, the profiles of the simulated geometry and experimentally manufactured geometry are only shifted against each other as only the radius of the tool is engaged. The displacement takes place in $z_{M \text { - }}$ and $y$-, respectively, $x_{M}$-direction. In the application case considered, this means that the simulated profile lies deeper below the workpiece surface: The cutting depth is greater. Since no material properties are taken into account in the simulation, this fact is irrelevant.

Thus, it was checked whether the tool gets in contact with its shaft at the tilt angles set in the experiment for the tested geometries. When the tool is engaged with its shaft, the total angle of inclination (local gradient angle of the geometry plus tilt angle) between the tool and the workpiece must be larger than $90^{\circ}$ (see Figure 11).

The angle of the local gradient of the sinusoidal structures (ACS, PPS, and PPS rotated) amounts to a maximum of $8.93^{\circ}$ for the manufactured sinusoidal geometries. The local gradient for the AFL geometry is constant at $0^{\circ}$. The total angle of inclination is thus $68,93^{\circ}$ for the sinusoidal structures and $60^{\circ}$ for the AFL geometry at the maximum examined tilt angle of $60^{\circ}$. This means that the shaft is not engaged during the simulation, and the contact point can be relocated to simplify the simulation.

The manufacturing of all datasets from the experimental study (see [32]) was simulated. Analogous to the experimental study, surface texture parameters were derived from the simulated topographies (see Table 4). Since the deviations of the results for the different tilt angles were smaller than one nanometer, only the mean values from all simulations (for the nine different tilt angles) are given. The deviations in the nanometer range at different tilt angles confirm that the tool is only engaged with its ball end for all tested tilt angles. 
Figure 10 Resulting geometry after manufacturing and simulation

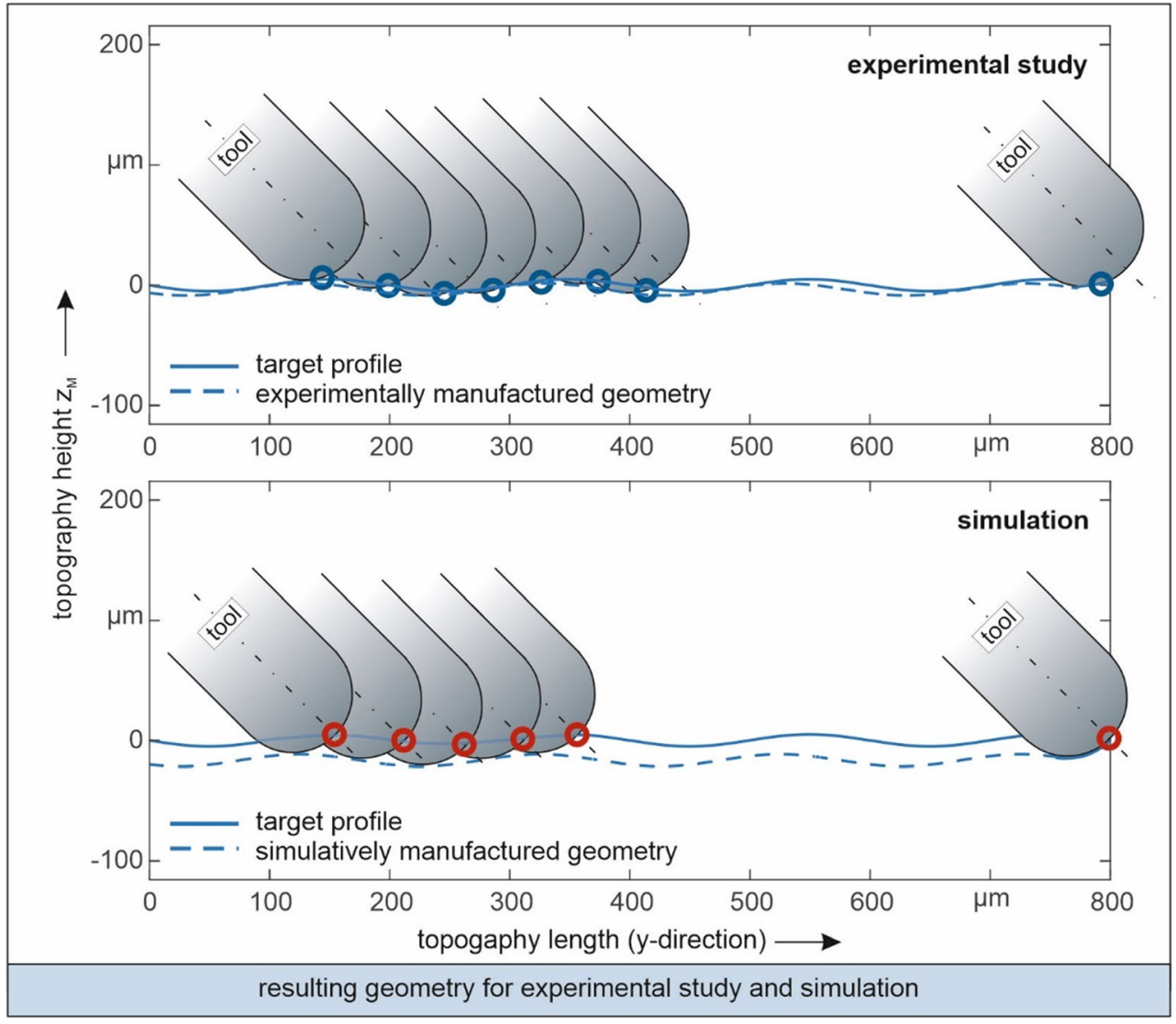

When compared with the experimental data, the parameters are very close to the mean values of the experimental study (see Figure 12). The absolute differences between the mean values of the experimentally determined surface texture parameters, and the simulatively determined parameters are less than $56 \mathrm{~nm}$ (see Figure 12). In percentage, this results in deviations of less than $1.8 \%$ for the sinusoidal structures (see Figure 12). For the AFL geometry, the nominal roughness equals zero, and the percentage deviation is no reasonable evaluation criterion. For this geometry, therefore, only the absolute deviation is considered. The deviations from the experiment can be justified by the fact that in addition to the kinematic effects, other effects, such as the cutting mechanism, also play a role in the experiment. In the simulation, however, only kinematic influences were included. The elastic and plastic deformation of the workpiece material was not taken into account, since a material-independent consideration was carried out within the scope of this study. Nevertheless, such effects have a considerable influence on the dimensional accuracy of the milled surface during the experiments. However, to minimize the influence, an easily machinable material was selected.

Additional deviations occur because of the simplified tool model (envelope curve).
The simulation is validated for further studies based on the very good conformity of the results from the experiment and the simulation.

It is now possible to investigate which kinematically caused deviations from the nominal geometry to occur at which milling tool radii. Thus, it can be determined which tool radii are unsuitable for the manufacturing of the small sinusoidal structures according to ISO 25178-70 [1].

\section{Influence of the tool radius}

Based on the investigations from Sections 3.1 and 3.2, the following simulation model resulted (see Table 5).

The manufacturing of the ACS geometry $(d=10 \mu \mathrm{m}$ and $p=200 \mu \mathrm{m}$ ) was simulated for different tool diameters. The ACS geometry was chosen because it features sinusoidal oscillations in both lateral directions. Thus, the tool diameter influences this sinusoidal structure in two directions with different discretization (distance between two tool paths $L$ in $x_{M^{-}}$ direction and discretization along tool path $D$ in $y$-direction).

Tool radii from $5 \mu \mathrm{m}$ to $250 \mu \mathrm{m}$ were tested in the radius study. The evaluated surface texture parameters as well as the corresponding target parameters are given in Table 6, and the 


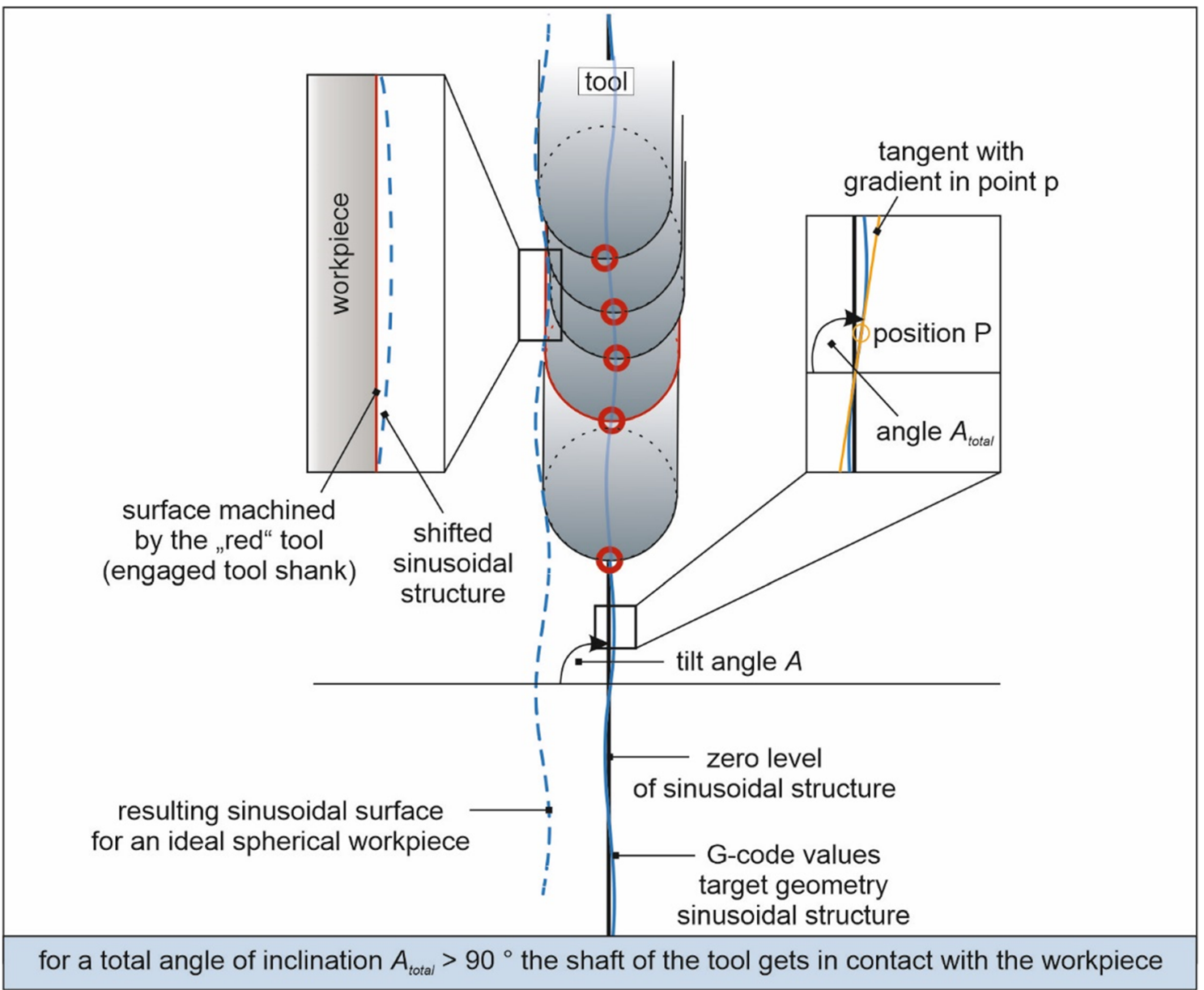

Figure 11 Critical total angle of inclination

topographies of the simulative manufacturing are pictured in Figure 13.

For very small tool radii $\left(r_{\mathrm{sim}, 1}=5 \mu \mathrm{m}\right)$, the shortwavelength surface texture parameters $\mathrm{Sa} 80, \mathrm{Sq} 80, \mathrm{Sa05}-25$, and $S q 05-25$ are relatively high, as expected (see Figure 6), but the dimensional accuracy of the structure is generally well imaged (see Figure 13). Due to the higher short-wavelength roughness for small tool radii (see Figure 6), however, deviations for the parameters $S a$ and $S q$ are present. As the tool radius increases, the short-wavelength roughness initially decreases in $x_{M^{-}}$-direction (see Figure 6) and $S a$ and $S q$ are better imaged. The target parameter $S a$ is best met at $r_{\mathrm{sim}, 3}=50 \mu \mathrm{m}$, and the target parameter $S q$ is best met at $r_{\mathrm{sim}, 4}=75 \mu \mathrm{m}$. Nevertheless, deviations in the dimensional accuracy can already be detected in these topographies (see Figure 13). As the radius increases, the deviations from the target geometry become larger and the $S a$ and $S q$ values also deviate increasingly. The topographies in Figure 13 clearly show that the valleys
Table 4 Surface texture parameters for simulatively manufactured geometries $\left(r_{\text {sim }}=100 \mu \mathrm{m}\right)$

\begin{tabular}{|c|c|c|c|c|c|c|c|c|}
\hline \multirow[t]{2}{*}{ Geom. } & \multicolumn{2}{|c|}{$\begin{array}{l}\text { Target values } \\
\text { (intended values) }\end{array}$} & \multicolumn{6}{|c|}{ Evaluated parameters for simulated topographies } \\
\hline & $\begin{array}{l}\mathrm{Sa} \\
(\mu \mathrm{m})\end{array}$ & $\begin{array}{l}S q \\
(\mu \mathrm{m})\end{array}$ & $\begin{array}{l}S a \\
(\mu \mathrm{m})\end{array}$ & $\begin{array}{l}S q \\
(\mu \mathrm{m})\end{array}$ & $\begin{array}{l}\text { Sa80 } \\
(\mu \mathrm{m})\end{array}$ & $\begin{array}{l}S q 80 \\
(\mu \mathrm{m})\end{array}$ & $\begin{array}{l}\text { Sa05-25 } \\
(\mu \mathrm{m})\end{array}$ & $\begin{array}{l}S q 05-25 \\
(\mu \mathrm{m})\end{array}$ \\
\hline ACS & 2.012 & 2.493 & 2.000 & 2.439 & 0.431 & 0.513 & 0.047 & 0.056 \\
\hline PPS & 3.180 & 3.534 & 3.077 & 3.452 & 0.332 & 0.394 & 0.033 & 0.041 \\
\hline $\begin{array}{l}\text { PPS } \\
\quad \text { rotated }\end{array}$ & 3.163 & 3.527 & 3.080 & 3.453 & 0.333 & 0.392 & 0.033 & 0.040 \\
\hline AFL & 0.000 & 0.000 & 0.005 & 0.006 & 0.005 & 0.006 & 0.002 & 0.002 \\
\hline
\end{tabular}




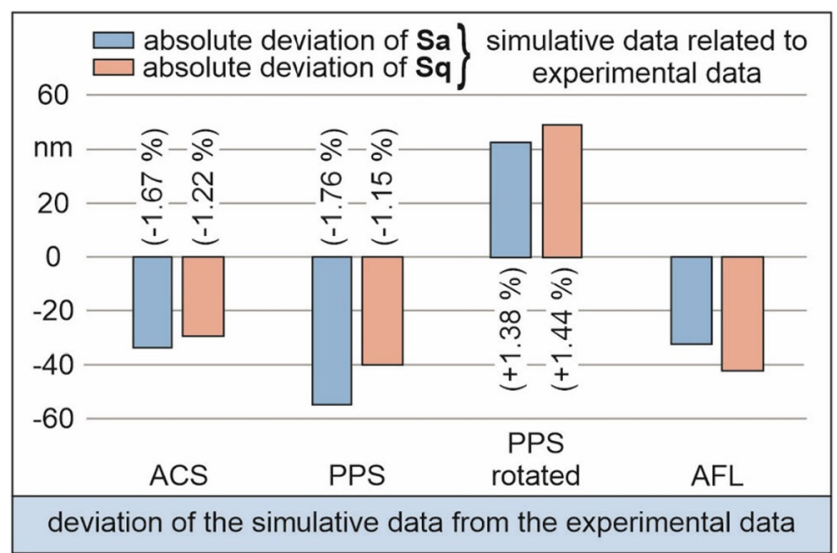

Figure 12 Comparison of simulatively and experimentally manufactured geometries (surface texture parameters)

of the topography become more and more circular and that the peaks of the topographies first become square and then starshaped for increasing radii. To characterize these deviations from the target geometry more precisely, a single profile was examined more closely in a two-dimensional examination.

The profile case is easier to implement in Matlab ${ }^{1}$ because only a two-dimensional tool (circle) and a profile sinus are simulated. However, CutS is mainly optimized for performing three-dimensional simulations and was therefore used exclusively for three-dimensional simulations in this study. Due to the reduction to $2 \mathrm{D}$, the Matlab ${ }^{1}$ simulation runs in a computing time of $<5 \mathrm{~min}$. This means that the profile case can be tested quickly for a large number of tools.

In Matlab ${ }^{1}$, a profile sine structure $(d=10 \mu \mathrm{m}, p=200 \mu \mathrm{m})$ was imaged with a circle with a variable radius. The circle was placed to all points of the sine structure (lateral shifted with 0.1 $\mu \mathrm{m})$. The resulting profile, taking the tool diameter into account, was determined. Figure 14 exemplarily shows the resulting profile for a circle with $r_{\mathrm{sim}, 1}=5 \mu \mathrm{m}$ and $r_{\mathrm{sim}, 7}=$ $200 \mu \mathrm{m}$.

The valleys of the structure become wider and the peaks narrower for large tool diameters $\left(r_{\mathrm{sim}, 7}\right)$. The highest point of the peak of the structure can be still imaged by the tool, but the flanks of the peaks are cut. If a zero baseline for the calculation of the surface texture parameters is placed in the resulting profile after simulative manufacturing, this baseline is closer to the minimum profile point than with an ideal profile due to the different geometry of the structure. The peaks are much higher in relation to this zero baseline, but also much narrower (short-wavelength) with regard to the target geometry. The valleys are less deep, but much wider. These observations explain the deviations of the geometries in Figure 13, and the changes of the surface texture parameters as shown in Table 6.

In summary, the radius study shows that the tool radius influences the dimensional accuracy of the structure in two different ways: on the one hand, the overlapping of the milling paths during path change (see Figure 6) results in a shortwavelength roughness, which causes the deviation from the target geometry, especially with small tool radii. On the other hand, deviations result from the fact that the milling tool can no longer correctly map areas of the convex structure in the area of the profile peaks. The second effect occurs particularly with large tool radii. Both effects can be made visible using kinematic simulation. The model can be used for an optimization of the tool radius with regard to the manufacturing of a specific geometry. In the present case, the ideal tool radius can be considered as $50-75 \mu \mathrm{m}$.
Table 5 Overview simulation model

\begin{tabular}{ll}
\hline & Setup/software used \\
\hline Software & CutS (IFW) \\
Workpiece model & - Dexel model \\
& - Dexels only in one direction: $z_{M}$-direction \\
& - Modeled size: $300 \mu \mathrm{m} \times 300 \mu \mathrm{m}$ \\
Tool model & - STL file; 65,520 factes \\
& - Modeled in CAD-sofware Siemens $\mathrm{NX}^{\mathrm{a}}$ \\
Relative motion (G-Code) & - Same as for experimental studies \\
& - Distance between two tool path $L=4 \mu \mathrm{m}$ \\
& - Discretization in feed direction: $D=0.8 \mu \mathrm{m}$ \\
Simulative feed rate & - Tilt angle: $20^{\circ}$ \\
Swept volume & -0.4 mm/min \\
& - One dexel per time step \\
& - Not calculated; simulative feed-rate was adepted \\
\hline
\end{tabular}


Table 6 Surface texture parameters for different tool radii (ACS geometry), simulation results

\begin{tabular}{lllllll}
\hline Tool radius $(\mu \mathrm{m})$ & $\mathrm{Sa}(\mu \mathrm{m})$ & $\mathrm{Sq}(\mu \mathrm{m})$ & $\mathrm{Sa} 80(\mu \mathrm{m})$ & $\mathrm{Sq} 80(\mu \mathrm{m})$ & $\mathrm{Sa05-25}(\mu \mathrm{m})$ & $\mathrm{Sq05-25}(\mu \mathrm{m})$ \\
\hline 5 & 2.027 & 2.500 & 0.417 & 0.520 & 0.054 & 0.066 \\
25 & 2.024 & 2.493 & 0.406 & 0.498 & 0.043 & 0.052 \\
50 & 2.021 & 2.482 & 0.413 & 0.501 & 0.044 & 0.053 \\
75 & 2.013 & 2.465 & 0.422 & 0.506 & 0.045 & 0.054 \\
100 & 2.001 & 2.439 & 0.431 & 0.513 & 0.047 & 0.056 \\
150 & 1.951 & 2.366 & 0.445 & 0.529 & 0.051 & 0.064 \\
200 & 1.868 & 2.260 & 0.447 & 0.540 & 0.055 & 0.077 \\
250 & 1.766 & 2.132 & 0.441 & 0.533 & 0.060 & 0.090 \\
Target & 2.012 & 2.493 & & & & \\
\hline
\end{tabular}

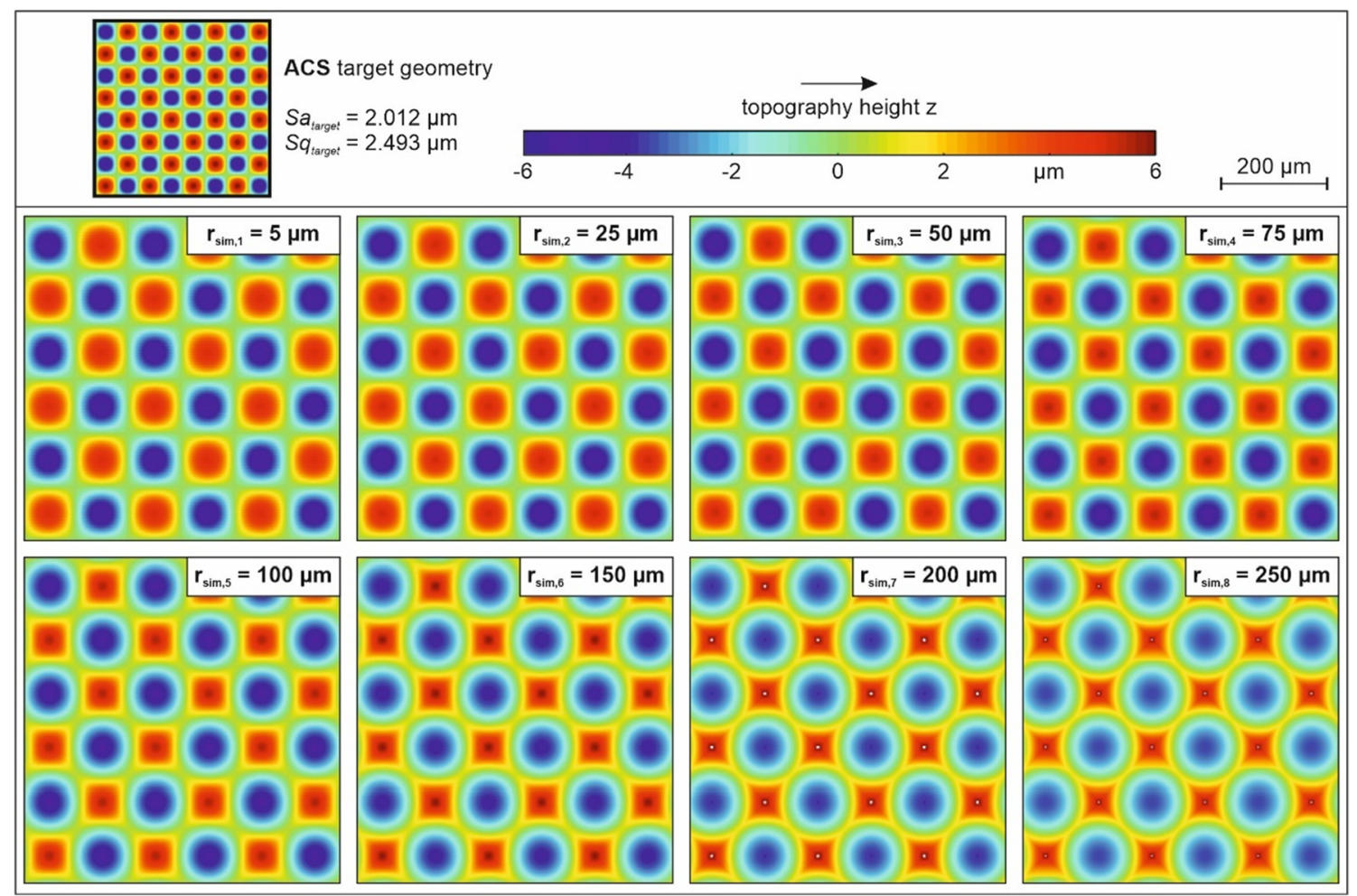

Figure 13 Topographies of simulatively manufactured geometries with different tool radii

Figure 14 Dimensional accuracy of the simulated structure for different tool radii (simulated in Matlab $^{1}$ )

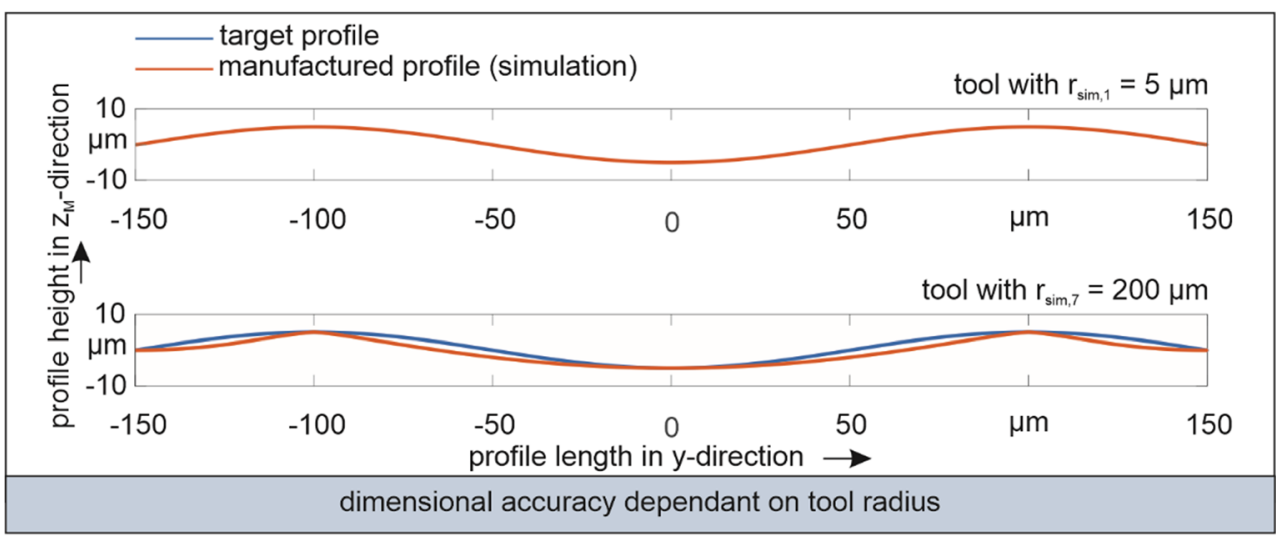




\section{Conclusion and outlook}

A simulation model for micro-milling of areal material measures with ball end mills was built. The model was simplified to shorten the computing time. The model simplifications presented in this paper can be transferred to other micro-milling processes. They were verified by comparison of the areal surface texture parameters. The simplified model was validated against experimental studies performed in previous work. With the validated model, it is possible to calculate the kinematically caused deviations (due to the tool radius and chosen tool path) from the nominal geometry for the described process. It is also possible to select suitable tool radii for the target geometry. The benefit of this study is that it not only can be checked whether deviations from the target geometry occur but that the resulting topography can be calculated threedimensionally and evaluated analogously to experimental data.

The developed simulation model can be used for any ball end micro-milling application, where very small structure sizes have to be manufactured with the smallest possible deviations. Compared to the morphological filtering used so far in the design of material measures, the approach described offers considerable advantages: the feed path (surface generation strategy) is taken into account in the model and can be adapted to the parameter settings of the experiment. Thus, the choice of feed path, which can also have a significant influence on dimensional accuracy, is considered.

Because the G-Code, which was also used for the experimental studies, can be imported, the simulation can also be applied to very irregular freeform surfaces, which cannot be easily described analytically. The presented simulation can therefore also be applied to novel material measures based on real component surfaces.

In further studies, the influence of the workpiece material should also be taken into account, because this can also result in deviations from the nominal geometry. Both elastic and plastic deformation of the material should be considered.

Additionally, the influence of the geometry and topography of the cutting edge will also be taken into account to simulate the kinematic roughness.

Acknowledgements Funded by the Deutsche Forschungsgemeinschaft (DFG, German Research Foundation) - project number 172116086 SFB 926.

Availability of data and materials Not applicable.

Author contribution Katja Klauer: conceptualization, methodology, formal analysis, and writing - original draft. Matthias Eifler: conceptualization, methodology, formal analysis, and writing - original draft. Benjamin Kirsch: conceptualization, project administration, writing - review and edition, and supervision. Volker Böß: conceptualization, software, methodology, and writing - review and edition. Jörg Seewig: conceptualization, supervision, and funding acquisition. Jan C. Aurich: conceptualization, supervision, and funding acquisition.

Funding Open Access funding enabled and organized by Projekt DEAL. Funded by the Deutsche Forschungsgemeinschaft (DFG, German Research Foundation) - project number 172116086 - SFB 926.

\section{Declarations}

Ethics approval Not applicable.

Consent to participate Not applicable.

Consent for publication Not applicable.

Competing interests The authors declare no competing interests.

Open Access This article is licensed under a Creative Commons Attribution 4.0 International License, which permits use, sharing, adaptation, distribution and reproduction in any medium or format, as long as you give appropriate credit to the original author(s) and the source, provide a link to the Creative Commons licence, and indicate if changes were made. The images or other third party material in this article are included in the article's Creative Commons licence, unless indicated otherwise in a credit line to the material. If material is not included in the article's Creative Commons licence and your intended use is not permitted by statutory regulation or exceeds the permitted use, you will need to obtain permission directly from the copyright holder. To view a copy of this licence, visit http://creativecommons.org/licenses/by/4.0/.

\section{References}

1. ISO 25178-70, (2014) Geometrical product specifications (GPS) surface texture: Areal - Part 70: Material measures (ISO 25178-70: 2014)

2. Aurich JC, Reichenbach I, Bohley M (2014) Ultra-small micro end mills. CIRP Encyclopedia of Production Engnieering. Springer Reference, pp 1280-1286

3. Cheng K, Dehong H (2013) Micro-cutting: fundamentals and applications. Wiley \& Sons, Oxford

4. Brinksmeier E (2014) Diamond machining. In: CIRP Enyclopedia of Production Engineering. Springer Verlag, Berlin-Heidelberg

5. Nemoto K, Yanagi K, Aketagawa M, Yoshida I, Uchidate M, Miyaguchi T, Maruyama H (2009) Development of a roughness measurement standard with irregular surface topography for improving 3D surface texture measurement. Meas Sci Technol 20: 084023

6. Leach R, Giusca C, Rickens K, Riemer O, Rubert P (2014) Development of material measures for performance verifying surface topography measuring instruments. Surface Topography: Metrology and Properties 2:025002

7. Eifler M, Klauer K, Kirsch B, Seewig J, Aurich JC (2018) Micromilling of areal material measures - influences on the resulting surface topography. Procedia CIRP 71:122-127

8. Klauer K, Eifler M, Kirsch B, Seewig J, Aurich JC (2020) Correlation between different cutting conditions, surface roughness and dimensional accuracy when ball end micro milling material measures with freeform surfaces. Mach Sci Technol 24(3):446-464 
9. Arrazola PJ, Özel T, Umbrello D, Davies M, Jawahir IS (2013) Recent advances in modelling of metal machining processes. CIRP Ann Manuf Technol 62:695-718

10. Eifler M, Klauer K, Kirsch B, Aurich JC, Seewig J (2020) Performance verification of surface texture measuring instruments with the Sk-parameters. Measurement 173:108550. https://doi.org/ 10.1016/j.measurement.2020.108550

11. Eifler M (2016) Modellbasierte Entwicklung von Kalibriernormalen zur geometrischen Produktspezifikation. Technische Universität Kaiserslautern

12. Weckenmann A, Weidenhöfer T, Büttgenbach S, Krah T, Fleischer J, Buchholz I, Viering B, Kranzmann A, Ritter M, Krüger-Sehm R, Bakucz P, Schmitt R, Koerfer F (2008) Trends bei der Entwicklung von Normalen für die Mikro- und Nanomesstechnik: Herausforderungen und Lösungsansätze. Tm- Technisches Messen 5(2008):288-297

13. Krüger-Sehm R, Bakucz P, Jung L, Wilhelms H (2007) Chirp calibration standards for surface measuring instruments, tm Technisches Messen 74 11, 572-576

14. Choi BK, Jerard RB (1998) Sculptured surface machining: theory and applications. Springer Science + Business Media B. V

15. Denkena B, Böß V, Nespor D, Gilge P, Hohenstein S, Seume J (2015) Prediction of the 3D surface topography after ball end milling and its influence on aerodynamics. Procedia CIRP 31:221-227

16. Tapoglou N, Antoniadis A (2012) 3-Dimensional kinematics simulation of face milling. Measurement 45:1396-1405

17. Wojciechowski S, Wiachiewicz M, Kroczyk GM (2018) Study on metrological relations between instant tool displacements and surface roughness during precise ball end milling. Measurement 129: 686-694

18. Zhan J, Zhang S, Jiang D, Wang J, Lu S (2020) Suface topography model with considering corner radius and diameter of ball-nose end miller. The International Journal of Advanced Manufactrung Technology 106:3975-3984

19. Pimenoc DY, Hassui A, Wojciechowski S, Mia M, Magri A, Suyama D, Bustillo A, Krolczyk G, Gupta MK (2019) Effect of the relative prosition of the face milling tool towards the workpiece on machined surface roughness and milling dynamics. Appl Sci 9: 842

20. Peng Z, Jiao L, Yan P, Yuan M, Gao S, Jie Y, Wang X (2018) Simulation and experimental study on 3D surface topography in micro-ball-end milling. Int J Adv Manuf Technol 96:1943-1958

21. Peng F, Wu J, Fang Z, Yuan S, Yan R, Bai Q (2013) Modeling and controlling of surface micro-topography frature in micro-ball-end milling. Int J Adv Manuf Technol 67:2657-2670

22. Kong LB, Cheung CF, To S, Lee WB, Du JJ, Zhan ZJ (2008) A kinematics and experimental analysis of form error compensation in ultra-precision maching. Int J Mach Tool Manu 48:1408-1419
23. Lee WB, Cheung CF, Chiu MW, Leung TP (2000) An investigation on residual form error compensation in the ultra-precision machining of aspherical surfaces. J Mater Process Technol 99:129134

24. Brinksmeier E, Riemer O, Osmer J (2008) Tool path generation for ultra-precision machining of free-form surfaces. Production Engineering Research and Development 2:241-246

25. Antoniadis A, Savakis C, Bilalis N, Baloukzsis A (2003) Prediction of surface topomorphy and roughness in ball-end milling. The International Journal of Advanced Manufacturing Technologie 21:965-971

26. Niebuhr C (2017) FE-CutS - Finite Elemente Modell für makroskopische Zerspanprozesse; Modellierung. Universität Bremen, Analyse und Simulation

27. van Hook T (1986) Real-time shaded NC milling display. ACM SIGGRAPH Computer Graphics 20(4):15-20

28. Börner R, Winkler S, Junge T, Titsch C, Schubert A, Drossel WG (2018) Generation of functional surfaces by using a simulation tool for surface prediction and micro structuring of cold-working steel with ultrasonic vibration assisted face milling. J Mater Process Technol 255:749-759

29. Denkena B, Tönshoff HK (2011) Spanen Grundlagen - 3. Auflage. Springer-Verlag, Berlin-Heidelberg

30. Lee SW (2009) Simultan 5-Achs-Frässimulation zur Verifikation der Werkzeugbahnen. TU Dresden IFF PAZAT Forschungsbericht

31. Denkena B, Tracht K, Jae-Hak Y (2006) Advanced NC-simulation based on the dexelmodel and the HRMC-algorithm. Production Engineering - Research and Development in Germany XIII/1: 9194

32. Klauer K, Eifler M, Kirsch B, Seewig J, Aurich JC (2020) Ball end micro milling of areal material measures - influence of the tilt angle on the resulting surface topography. Production Engineering Research and Development 14:239-252

33. ISO 25178-2 (2012). Geometrical product specifications (GPS) surface texture: Areal - Part 2: Terms, definitions and surface texture parameters

34. Hock S (1996) Hochgeschwindigkeitsfräsen im Werkzeug- und Großformenbau - Eingriffsverhältnisse und Technologie. Darmstädter Forschungsberichte für Konstruktion und Fertigung. Shaker Verlag

Publisher's note Springer Nature remains neutral with regard to jurisdictional claims in published maps and institutional affiliations. 